\title{
Um espaço todo nosso
}

Mulher e Literatura - 25 anos: raízes e rumos

STEVENS, Cristina (Org.).

Florianópolis: Editora Mulheres, 2010. 280 p.

A coletânea de ensaios, que marca os 25 anos do Grupo de Trabalho A Mulher na Literatura da Associação Nacional de Pós-Graduação e Pesquisa em Letras e Linguística - Anpoll, celebra a existência, delineia a trajetória e reflete sobre o impacto do grupo de pesquisa, incluindo as mudanças de rumos e estratégias ao longo dos anos. Os ensaios demonstram uma preocupação de ir além da coleta e análise de dados, refletindo sobre os resultados, apontando ganhos, revelando incongruências, sugerindo rumos. Organizada por Cristina Stevens, a publicação reúne 14 artigos que suscitam o interesse não só dos membros do GT, mas também de qualquer pesquisador/a da literatura produzida por mulheres no Brasil e em outras partes do mundo.

Antes de prosseguir com a resenha, gostaria de explicitar meu local de fala. Minha trajetória de pesquisa sobre as questões de gênero se estende por mais de duas décadas. Atualmente sou líder da Linha de Pesquisa "A voz e o olhar do Outro: questões de gênero e/ou etnia nas literaturas de língua inglesa" do mestrado em Literaturas em Língua Inglesa da Pós-Graduação em Literatura da Universidade do Estado do Rio de Janeiro e do GrPesq/CNPq. Desde 1998, quando passei a ser integrante da Linha, trabalho principalmente com literatura de expressão inglesa produzida por mulheres. Faço parte do GT A Mulher na Literatura desde 1999 e atuei na sua coordenação, junto com Ana 
Cecília Acioli Lima, durante o biênio 2008-2010. Ao ser convidada para escrever esta resenha, me senti honrada e ao mesmo tempo consciente da responsabilidade, portanto faço minhas as palavras de Rita Terezinha Schmidt no último ensaio da coletânea, quando afirma que suas observações "não têm, em absoluto, a pretensão de explorar toda a riqueza de dados, das relações e reflexões apresentadas nos textos que compõem [a] coletânea" (p. 258).

A "Apresentação", escrita por Susana Bornéo Funk, coloca em tela as raízes e os rumos do grupo de pesquisa e abre caminho para um mapeamento e a análise abrangentes e detalhados das áreas de atuação do GT. Na retrospectiva histórica do $\mathrm{GT}$, desde o primeiro Encontro em 1985 até o período que antecedeu o XXV Encontro Nacional da Anpoll em 2010, Constância Lima Duarte caracteriza o GT como um espaço que acolhe a diversidade de interesses e estimula o diálogo com outras disciplinas. Percebemos, através do relato meticuloso, que a história do GT está intimamente ligada não só à história da literatura produzida por mulheres no Brasil como também ao desenvolvimento dos estudos de gênero no país. Já o registro das mudanças de configuração, ao longo dos anos, nas linhas de pesquisa que constituem o GT coloca em evidência a natureza dinâmica do grupo.

As informações sobre eventos acadêmicos científicos nacionais e internacionais diretamente ligados ao GT são encontradas nos ensaios de Constância Lima Duarte e Elódia Xavier. O relato histórico de Duarte, que inclui o registro de todas as coordenações do GT, assinala os Encontros do GT durante o Seminário Nacional e Internacional da Anpoll, que ocorre a cada dois anos. Esses Encontros, restritos aos membros do GT, propiciam a oportunidade de discussões e trocas entre pares e envolvem a eleição da nova gestão, a avaliação do biênio e o planejamento geral dos próximos dois anos. Xavier discorre sobre a trajetória de sucesso do Seminário Mulher e Literatura, que ocorre nos anos ímpares e é aberto a docentes e discentes interessados nessa temática. Percebemos então que os Encontros e os Seminários se complementam: são momentos diferentes com objetivos diferentes.

O aumento do número de GTs e, mais importante ainda, o crescimento exponencial de Programas de Pós-Graduação em Literatura e Linguística nas últimas décadas não só restringem $\circ$ tempo dedicado às atividades específicas dos GTs durante os Encontros nacionais, mas também repercutem na organicidade da própria Anpoll, gerando problemas complexos que têm suscitado vários debates. Nesse ínterim, me parece que cabe aos GTs buscar soluções criativas, experimentar novos formatos. Os simpósios que organizamos no Encontro de 2010, por exemplo, conseguiram aglutinar pessoas com interesses afins, mas não permitiram que todos os participantes assistissem a todas as discussões. Por outro lado, na segunda manhã, a discussão liderada pelas responsáveis dos simpósios foi seguida por um processo de autoavaliação do grupo e de suas atividades que teve como frutos vários projetos já em andamento durante o biênio atual.

Outro evento acadêmico de grande interesse para quem trabalha com o binômio Mulher e Literatura é enfocado no ensaio de Tânia Ramos. O Seminário Internacional Fazendo Gênero, realizado na Universidade Federal de Santa Catarina a cada dois anos desde 1994 tornou-se o mais importante fórum de caráter interdisciplinar sobre estudos de gênero e estudos feministas no Brasil. Dos 285 artigos que fazem parte dos 13 livros produzidos a partir de trabalhos apresentados nos Seminários, mais de um terço abordam questões da literatura e da linguagem.

Cláudia Lima Costa usa o contexto latinoamericano como pano de fundo para uma teorização em torno dos conceitos de colonialidade do poder e colonialidade de gênero. Enquanto o estudo de Simone Pereira Schmidt privilegia um recorte específico, usando os periódicos Revista Estudos Feministas e Cadernos Pagu para fazer um levantamento e a classificação temática de artigos que abordam a intersecção entre gênero e raça e constituem um dos rumos da crítica feminista no Brasil, a pesquisa de Cristina Stevens se propõe a oferecer um panorama da produção teórica e crítica em estudos feministas e de gênero no Brasil que inclui o Jornal das Senhoras, marco fundador do periodismo feminino brasileiro, as publicações diretamente ligadas ao GT (boletins, anais e livros), assim como aquelas em M\&L, que figuram em periódicos acadêmicos nacionais. Ao longo de seu ensaio, Stevens registra "sensações ambíguas de otimismo e preocupação" (p. 154) e frisa a necessidade de fortalecer as articulações entre estudos literários e movimentos sociais.

No Brasil, falar da fortuna crítica sobre gênero, sobre a produção literária de autoria feminina, sobre estudos feministas, como observa Tânia Ramos, significa falar da Editora Mulheres, de Zahidé Muzart. E o ensaio de Muzart 
sobre a criação da Editora em 1995, sobre a recuperação da produção da mulher brasileira do século XIX, sobre as várias séries publicadas regularmente, pontua uma caminhada marcada por trabalho árduo, esforço coletivo e sucesso incontestável.

O estudo de Eliane Campello, que examina a inserção de integrantes do GT em grupos de pesquisa do CNPq, sinaliza $\circ$ grande envolvimento dos/as integrantes com pesquisas, frequentemente como líderes de grupos, assim como o aumento progressivo de obras publicadas. Cíntia Schwantes, que mapeia a produção acadêmica de integrantes, usando como parâmetro as orientações concluídas, indica um aumento expressivo no número de teses e dissertações em estudos literários a partir de um referencial de gênero. O estudo traz ainda outro dado bastante significativo: muitos/as integrantes do GT foram orientandos/as de outros/as integrantes, sinalizando "um continuum de pesquisas nos estudos de gênero em literatura" (p. 115).

Por outro lado, os ensaios também revelam alguns dados menos animadores. Como Campello observa, há uma discrepância entre a alta produção bibliográfica dos/as integrantes do GT e o reduzido número de bolsas de produtividade do CNPq. Já o estudo de Izabel Brandão constata que a participação de integrantes do GT em vários núcleos, redes ou institutos sobre gênero em instituições de ensino superior no Brasil não se traduz em visibilidade de suas pesquisas em tais contextos.

$\mathrm{Na}$ pesquisa eletrônica que Liane Schneider empreendeu, usando como corpus 34 instituições federais e seus respectivos programas de pós-graduação em Letras, os indicativos de estudos feministas ou de gênero estão amplamente presentes nos projetos individuais e/ou de grupos de pesquisadores/as. No entanto, as palavras "mulher", "feminismo", "feminista" e "gênero" não fazem parte dos títulos das áreas de concentração dos programas de pós-graduação em letras e raramente aparecem nos títulos das linhas de pesquisa Schneider problematiza a "dissonância entre os projetos de pesquisa d@s docentes, as linhas de pesquisa e as áreas de concentração dos programas em que estes se inserem" (p. 68). Virginia Leal Vasconcelos constata que, apesar dos avanços, a ambiguidade que paira sobre o rótulo "literatura feminina" é apenas um dos índices das assimetrias que persistem no campo literário.

Em consonância com as pesquisadoras que contribuíram para esta coletânea, Rita Terezinha Schmidt sintetiza os avanços da área de pesquisa feminista do GT, ao mesmo tempo que problematiza os impasses e estimula questionamentos necessários para que possamos continuar criando e mantendo espaços próprios e legítimos. Concluo aqui com as palavras de Schmidt sobre o longo caminho que temos a percorrer: "[...] é indispensável acreditar que as energias feministas no campo dos estudos literários têm a potencialidade de interferir no discurso crítico, revitalizar o ensino e fecundar uma agenda educativo-pedagógica capaz de interromper as continuidades históricas das exclusões, da violência do preconceito" ( $p$. 270). Aos próximos 25 anos!

Leila Assumpção Harris Universidade do Estado do Rio de Janeiro 